\title{
DEVELOPMENT OF CHROMATE-FREE PASSIVATION PROCESSES FOR MAGNESIUM ALLOY AZ31B
}

\author{
${ }^{1}$ Maria SIMONOVA, ${ }^{1}$ Aleksey ABRASHOV, ${ }^{1}$ Nelya GRIGORYAN, ${ }^{1}$ Tigran VAGRAMYAN, \\ 'Vladimir MEN'SHIKOV
}

${ }^{1}$ MUCTR - D. Mendeleev University of Chemical Technology of Russia, Moscow, Russia, simonovamas11@rambler.ru

https://doi.org/10.37904/metal.2020.3550

\begin{abstract}
The disadvantage of magnesium alloys is their low corrosion resistance due to high electronegativity. One of the most effective methods to improve the corrosion resistance of magnesium alloys is to form a conversion adhesive coating on their surface, followed by applying paintwork materials. Chromatic coatings are widely used as adhesion layers under the paintwork before staining magnesium and its alloys. In recent years, in world practice, as an alternative to chromate layers on magnesium and its alloys, nanoscale conversion titanand/or zirconium- containing, and cerium-containing adhesive coatings have been used. The present work is devoted to the development of the technology for producing these coatings. It has been established that the developed passivating coatings based on the AZ31B magnesium alloy are comparable with chromate coatings in terms of corrosion resistance and protective ability. It has been established that coatings with developed adhesive sublayers have a higher adhesion strength to the base compared to coatings with chromate adhesive sublayer.
\end{abstract}

Keywords: Titanium-, zirconium-containing coatings, cerium-containing coating, corrosion protection, magnesium alloy, adhesive coatings, conversion coatings, surface treatment, chromate-free passivation

\section{INTRODUCTION}

In recent years, there has been an increase in the use of magnesium alloys as structural materials, due to the unique combination of properties: low specific gravity, high strength, ductility, damping ability and manufacturability. They are non-magnetic, possess excellent heat dissipation and 20 times more resistant to vibration than alloy steel. However, the use of magnesium and its alloys without additional protection against corrosion is impossible, since it corrodes rapidly, especially in aggressive conditions. One of the most effective methods of corrosion protection of magnesium alloys is the paint application. To ensure good adhesion of these coatings to the metal, an intermediate adhesion conversion sublayer is used, which not only provides good adhesion to the substrate, but can also provide additional coating protection. Prior to staining of magnesium and its alloys, chromate coatings are widely used as adhesive layers under paintwork. At the same time, it is known that hexavalent chromium compounds are very toxic and are carcinogens $[1,2]$.

As an alternative to chromate layers on other metal surfaces, nanoscale conversion titanium/zirconiumcontaining coatings and cerium-containing coatings have been increasingly used in recent years. In the literature there are some technologies for the application of functional coatings that do not contain chromium in their composition on magnesium alloys, however, the composition of solutions and process parameters are not disclosed by the authors. In this regard, the development of such solutions instead of chromating has become urgent for applying a conversion adhesive layer under LCP to magnesium alloys [3-12]. 


\section{EXPERIMENTAL MATERIALS}

Magnesium plates AZ31B were used as samples. Before coating, the following surface preparation was carried out:

1) surface etching in a solution consisting of: $\mathrm{NaOH}(40 \mathrm{~g} / \mathrm{l}), \mathrm{Na}_{2} \mathrm{SiO}_{3}(40 \mathrm{~g} / \mathrm{l})$ at $\mathrm{T}=25^{\circ} \mathrm{C}$ for 3 minutes;

2) surface activation in a solution of nitric acid $\left(\mathrm{HNO}_{3}(20-50 \mathrm{~g} / \mathrm{l})\right)$ for 1 minute;

After each stage, washing in distilled water was carried out.

The protective ability of the coatings was determined by the express method using a solution of lead acetate $\mathrm{Pb}\left(\mathrm{CH}_{3} \mathrm{COO}\right)_{2} 10 \mathrm{~g} / \mathrm{l}$. The criterion for assessing the quality of the coating was the time until the color of the control area under the drop changed from gray to dark black for the magnesium base.

Polarization measurements were performed using the IPC-Pro MF potentiostat in potentiodynamic mode at a sweep speed of $0.5 \mathrm{mV} / \mathrm{s}$. Samples of magnesium alloy with a protective PC in the studied solutions were used as working electrodes. The electrode potentials were measured relative to the silver chloride electrode, and their values were converted to the normal hydrogen scale.

The adhesion strength of the coatings was determined by normal separation method using a PosiTest AT adhesive meter. The method is based on measuring the minimum tensile stress required to separate or break the coating in a direction perpendicular to the surface of the substrate [14].

Corrosion tests of magnesium samples in combination with powder paint were carried out in a salt spray chamber of Ascott S450iP (Great Britain) in accordance with the international standard ASTM B117 [15]. The test was performed on stained samples with an X-shaped notch to the base metal, a width of not more than $0.5 \mathrm{~mm}$. Using compressed air, a $5 \% \mathrm{NaCl}$ solution was sprayed inside the chamber with the test samples in the form of fog. The samples were located in the chamber below the spray level of salt fog, which excluded the direct influence of salt fog on the samples.

\section{EXPERIMENTAL WORK}

Taking into account the literature information, solutions were prepared on the basis of hexafluorotitanic $\left(\mathrm{H}_{2} \mathrm{TiF}_{6}\right)$ and/or hexafluorozirconic $\left(\mathrm{H}_{2} \mathrm{ZrF}_{6}\right)$ acids, a nitrate salt of cerium $\left[\mathrm{Ce}\left(\mathrm{NO}_{3}\right)_{3} \cdot 6 \mathrm{H}_{2} \mathrm{O}\right]$ and hydrogen peroxide $\left(\mathrm{H}_{2} \mathrm{O}_{2}\right)$ as an oxidant.

\subsection{Determination of the titanium-, zirconium-containing coatings depositing process parameters}

The experiments carried out made it possible to determine the optimum concentration range of the solution components in which titanium-, zirconium-containing coatings are formed. It has been established that in the concentration range $0.2-1.0 \mathrm{~g} / \mathrm{l}$ of hexafluorotitanic acid $\left(\mathrm{H}_{2} \mathrm{TiF}_{6}\right), 1.5-2.0 \mathrm{~g} / \mathrm{l}$ of hexafluorozirconic acid $\left(\mathrm{H}_{2} \mathrm{ZrF}_{6}\right), 1.5-2.0 \mathrm{~g} / \mathrm{l}$ tartaric acid and 12-14 $\mathrm{g} / \mathrm{l}$ of hydroxyethane diphosphonic acid (HEDP) in the solution, homogeneous continuous coatings with a protective capacity (PC) of 14-16 s are formed on the surface of magnesium alloy [16].

As expected, the protective ability of coatings depends on the duration of their formation: it increases during the first 5 minutes of the process and then stabilizes. The presence of the coating in solution for more than 8 minutes is undesirable, as this leads to a decrease in their protective ability and an increase in the corrosion rate of the metal base.

The influence of the solution temperature on the properties of coatings was investigated and it was revealed that heating it to $40^{\circ} \mathrm{C}$ does not lead to significant changes in the appearance and protective ability of coatings, and at higher temperatures $\left(>40^{\circ} \mathrm{C}\right)$ their protective ability decreases. Therefore, over the operating range, an interval of $18-25^{\circ} \mathrm{C}$ was chosen.

Coatings of the best quality were obtained with titanium-, zirconium-containing coatings, when magnesium 
samples were immersed in a working solution at room temperature, at $\mathrm{pH}=4-5$ for 3 minutes. Then the samples were dried at a temperature of $70-80^{\circ} \mathrm{C}$.

\subsection{Determination of the cerium-containing coatings deposition process parameters}

It has been established that in the concentration $10 \mathrm{~g} / \mathrm{l}$ of cerium nitrate and $15-20 \mathrm{ml} / \mathrm{l}$ of hydrogen peroxide in the solution, homogeneous continuous coatings with a protective capacity of 11-15 s are formed on the surface of magnesium alloy. Studies have shown that the permissible $\mathrm{pH}$ values of solutions are in the range of 2.5-3.0.

It was experimentally established that the formation of cerium-containing coating is completed within $0.5-1.0$ minutes, while the protective ability of coatings reaches maximum (15 s).

The process temperature also affects cerium-containing coatings. It has been established that coatings of good quality are formed at a temperature of $40-50^{\circ} \mathrm{C}$. At a temperature below $40^{\circ} \mathrm{C}$, coatings do not form at all.

It is established that addition of PEG 1500 in the amount of $1.0 \mathrm{~g} / \mathrm{l}$ promotes better adhesion of the coating to the magnesium substrate.

\subsection{Tests of the coatings}

Using the PosiTest AT digital adhesion tester, the adhesion of paint coatings with adhesive titanium-, zirconium-containing and cerium-containing sublayers was determined. It was revealed that LPCs with these adhesive sublayers have a higher adhesion strength to the base compared to chromate coatings (Figure 1). The titanium-, zirconium-containing coating with the addition of HEDP adheres best to the surface of magnesium. Cerium coatings have less adhesion.

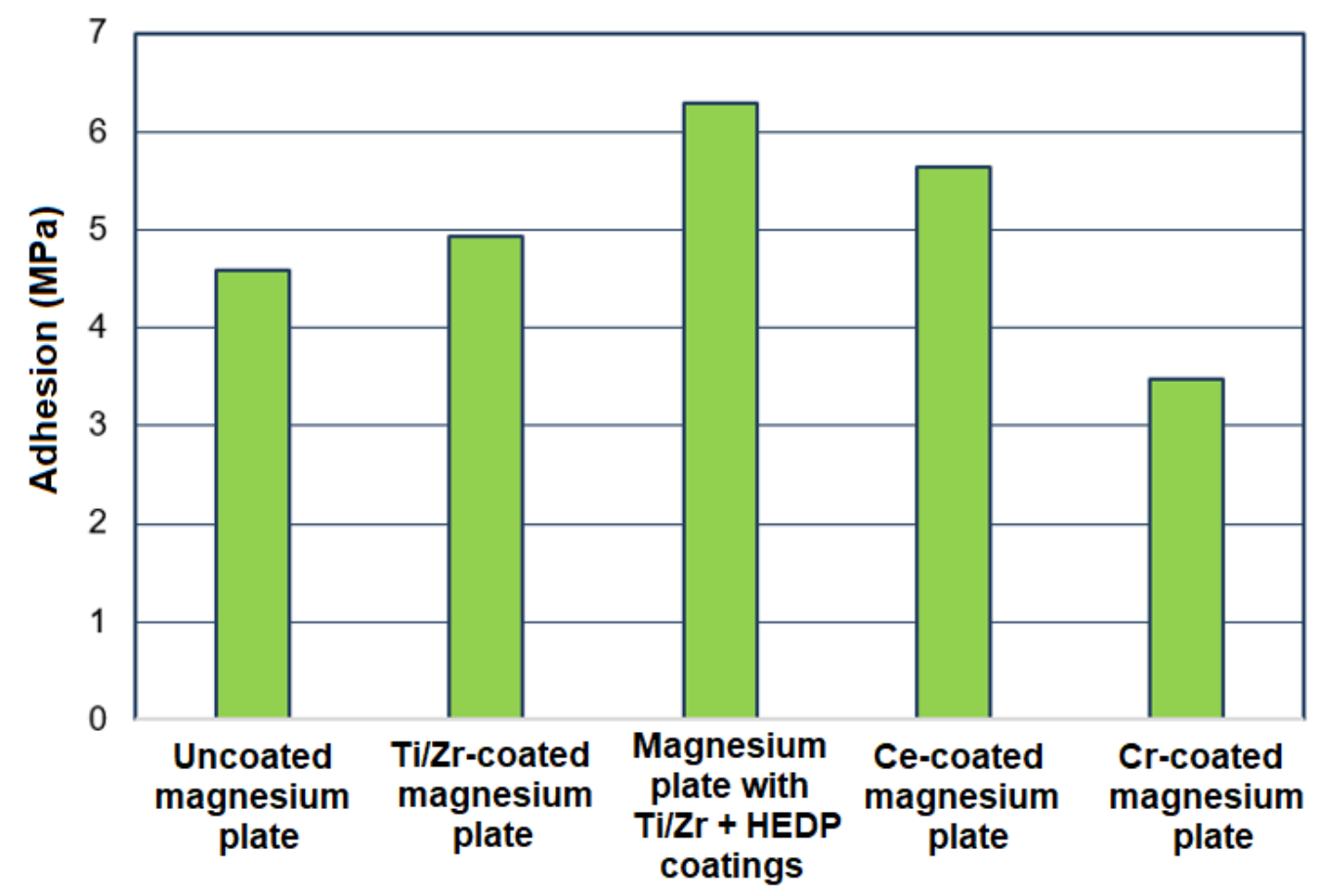

Figure 1 The results of determining the adhesion strength of coatings to the substrate

To assess the passivating effect of titanium, zirconium, and cerium compounds on a magnesium surface, the corrosion rate was determined electrochemically for the magnesium samples chromated and processed in titanium, zirconium, and cerium-containing solutions. Were obtained corrosion diagrams of these samples in 
a solution of $5 \% \mathrm{NaCl}$. A comparison of the corrosion rate values found from the corrosion diagrams shows that the corrosion resistance of magnesium passivated in a titanium and zirconium-containing solution with the addition of HEDP is higher than that of chromated magnesium (Figures 2-3). Corrosion rates are 4.03 and $4.71 \mathrm{~mA} / \mathrm{cm}^{2}$, respectively. Cerium coatings also have a lower corrosion rate than chromate coatings.

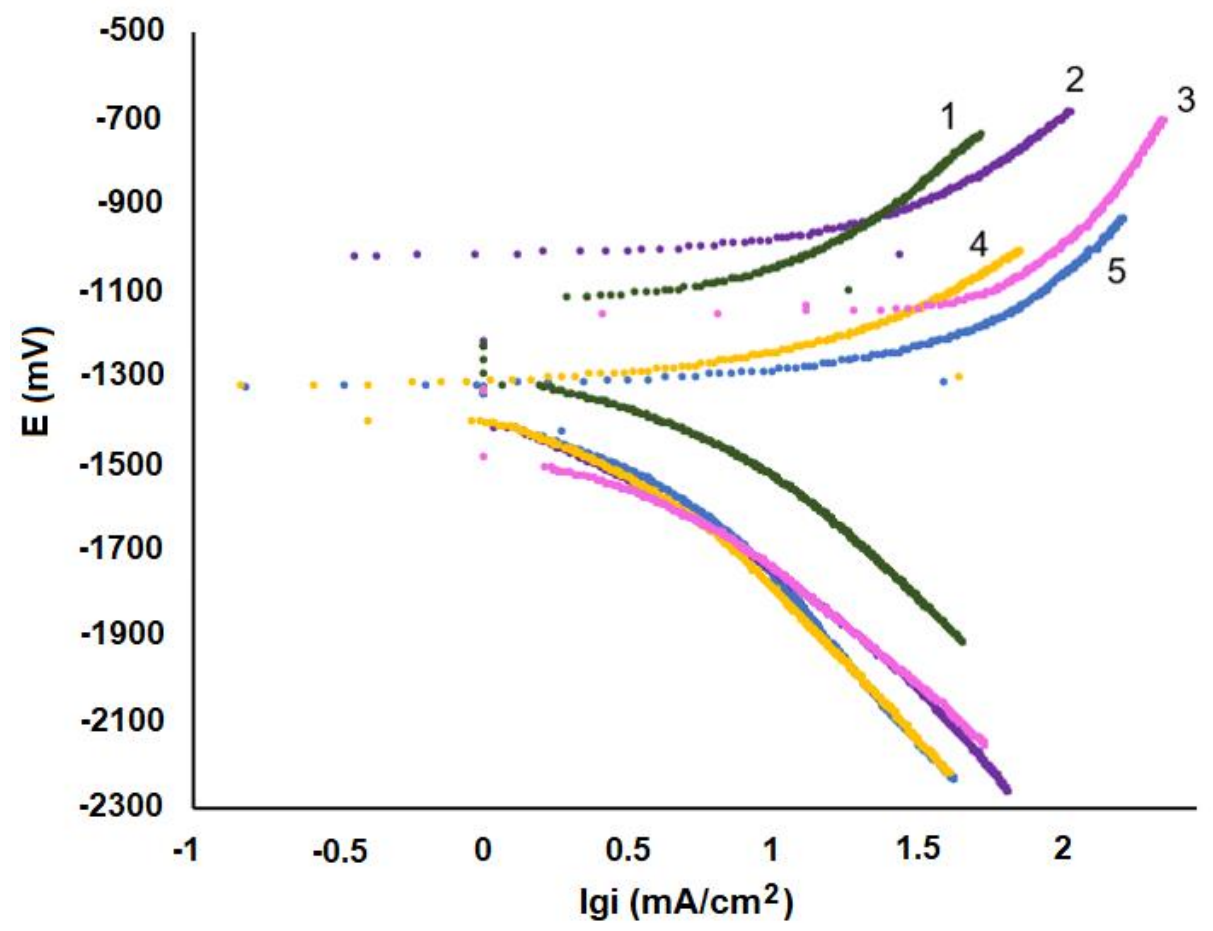

Figure 2 Polarization curves:

1 - Cr-coating; 2 - Ce-coating; 3 - Magnesium without coating; 4 - Ti/Zr-coating+HEDP; 5 - Ti/Zr-coating

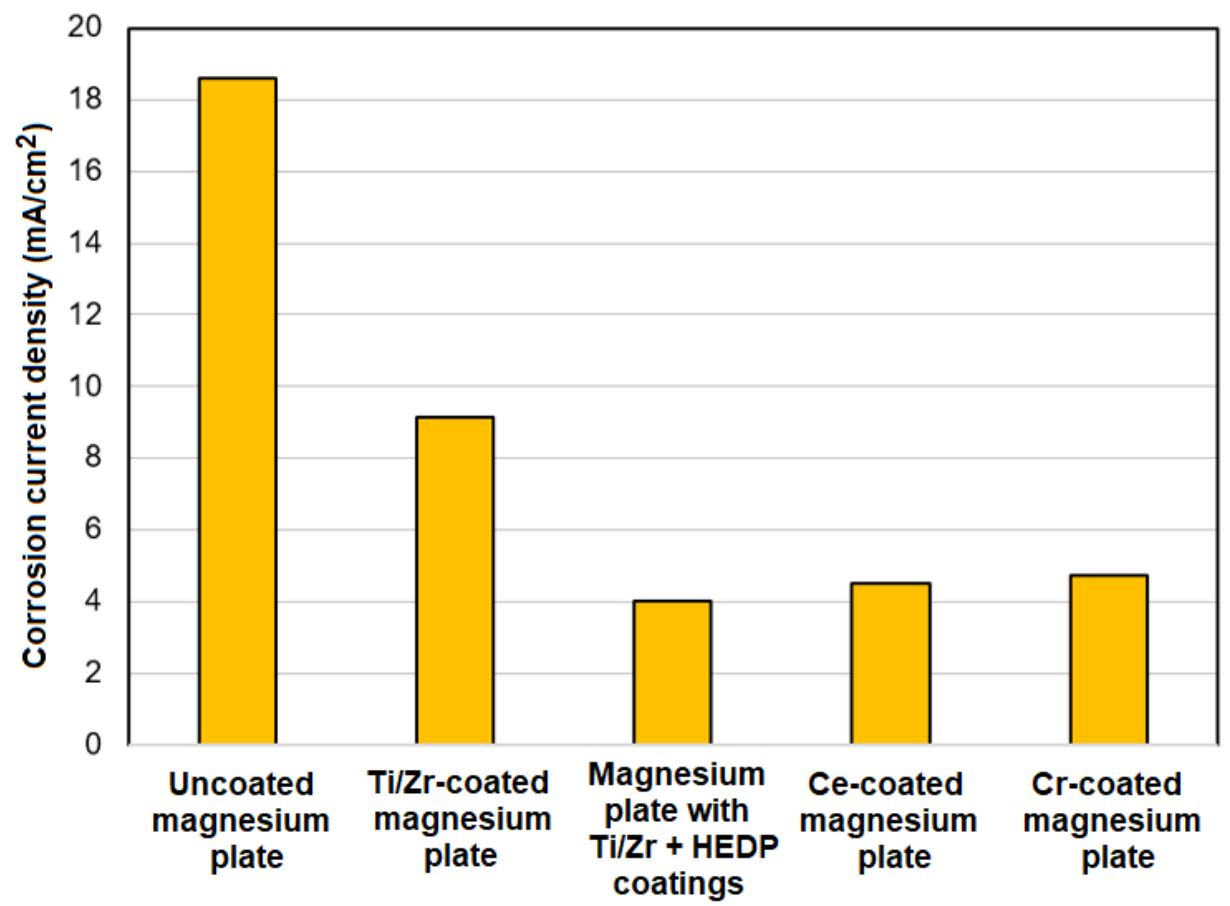

Figure 3 The results of determining the corrosion rate in a solution of $5 \% \mathrm{NaCl}$ 
Corrosion tests (ASTM B117) of polyester powder-coated magnesium specimens with developed adhesive coatings were compared with chromate coating (Figure 4). Tests have shown that the developed nanocoatings in terms of protective ability satisfy the requirements for adhesive layers under the paintwork, since the width of corrosion penetration from the place of incision in these cases does not exceed $2 \mathrm{~mm}$ after 100 hours of testing.

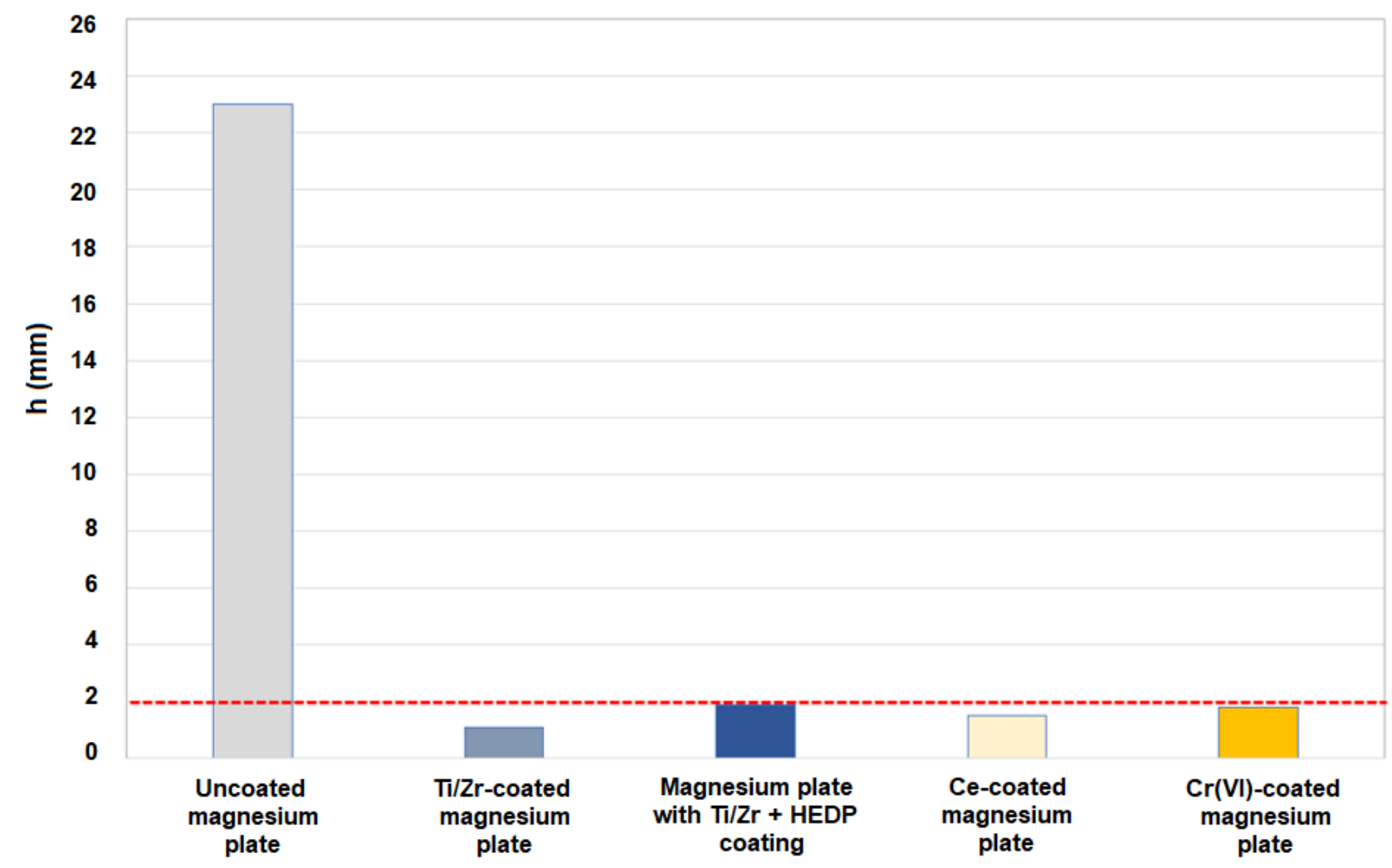

Figure 4 Results of corrosion tests (ASTM B117)

In addition, the results show that despite their lower thickness, they are not inferior to chromatic coatings in terms of their protective characteristics.

\section{CONCLUSION}

As a result of this study, it was shown that the developed titan-, zirconium-containing coating and ceriumcontaining coating on magnesium samples for corrosion resistance and protective ability are comparable to chromate coatings.

\section{ACKNOWLEDGEMENTS}

The work was supported by the Mendeleev University of Chemical Technology of Russia. Project Number X-2020-028

\section{REFERENCES}

[1] VISWANATHAN S. SAJI. Review of rare-earth-based conversion coatings for magnesium and its alloys. Journal of Materials Research and Technology. 2019, vol.8(5), pp.5012-5035.

[2] FUYONG CAO, GUANG-LING SONG, ANDREJ ATRENS. Corrosion and passivation of magnesium alloys. Corrosion Science. 2016, vol. 111, pp. 835-845. 
[3] CASTANO C. E., MADDELA S., O'KEEFE M. J., WANG Y. M. A comparative study on the corrosion resistance of cerium-based conversion coatings on az91d and az31b magnesium alloys. ECS Transactions. 2012, vol. 41, no.15, pp. 3-12.

[4] FUSHENG PAN, XU YANG, DENGFEI ZHANG. Chemical nature of phytic acid conversion coating on AZ61 magnesium alloy. Applied Surface Science. 2009, vol. 255, pp. 8363-8371.

[5] CHEN X. B., BIRBILIS N., ABBOTT T. B. Review of corrosion-resistant conversion coatings for magnesium and its alloys. Corrosion. 2011, vol. 67, no. 3, pp. 035005-1-035005-16.

[6] AIHUA YI, JUN DU, JIAN WANG ET AL. Preparation and characterization of colored Ti/Zr conversion coating on AZ91D magnesium alloy. Surface and Coatings Technology. 2015, vol. 276, pp. 239-247.

[7] GULBRANDSEN E., TAFTO J., OLSEN A. The passive behaviour of Mg in alkaline fluoride solutions. Electrochemical and electron microscopical investigations. Corrosion Science. 1993, vol. 34, no. 9, pp. 14231440.

[8] VERDIER S., VAN DER LAAK N., DELALANDE S. et al. The surface reactivity of a magnesium-aluminium alloy in acidic fluoride solutions studied by electrochemical techniques and XPS. Applied surface science. 2004, vol. 235, no. 4, pp. 513-524.

[9] CHIU K. Y., WONG M. H., CHENG F. T., MAN H. C. Characterization and corrosion studies of fluoride conversion coating on degradable mg implants. Surface and Coatings Technology. 2007, vol. 202, no 3, pp. 590-598.

[10] PAT. US 7402214 USA. Conversion coatings including alkaline earth metal fluoride complexes. Applied: 28.04.03. Published: 22.07.08.

[11] PAT. US 7175882 USA. Process for coating metal surfaces. Applied: 01.10.01. Published: 13.02.07.

[12] WOICIK J. C. Hard X-ray photoelectron spectroscopy (HAXPES). Springer International Publishing Switzerland, 2016. 571 p.

[13] LAHA P., SCHRAM T., TERRY H. Use of spectroscopic ellipsometry to study Zr/Ti films on al. Surfase Interface Analysis. 2002, vol. 34, no. 1, pp. 677-680.

[14] ASTM D4541-17. Standard Test Method for Pull-Off Strength of Coatings Using Portable Adhesion Testers.

[15] ASTM B117-11. Standard Practice for Operating Salt Spray (fog) Apparatus.

[16] ABRASHOV A.A., GRIGORYAN N.S., SIMONOVA M.A., ASNIS N.A. Adhesive conversion lacquer coatings on magnesium alloys. Tsvetnye Metally. 2019, no. 10 (922), pp.66-71. 